\section{Equality and Educational Justice}

Michael S. Merry

University of Amsterdam, Amsterdam

The Netherlands

All theories of justice aim to promote some good, or set of goods, for the benefit of persons such that the lives of individuals go reasonably well, and such that the benefits are fairly distributed in one way or another. All theories of justice further aim to specify, if only in broad strokes, the rights and responsibilities persons should have or enjoy, and how those rights and responsibilities should promote or at least compliment the interests of those possessing them. But strong theories of justice must also provide a justification for the coercive interference of the state, as well as some kind of principled guidance concerning how best to manage conflicting interests in deeply pluralist societies, where ideas about the good life sharply differ and where well-intended policies enacted by the state affect the lives of citizens in very different ways.

At the heart of any theory of justice lies the principle of equality. Taking equality seriously means that we ought to consider the ways in which persons are not only unfairly advantaged or disadvantaged from the start - e.g., through genetic inheritance, wealth, or a parent's educational background - but also how opportunities and rewards that result from these basic inequalities are later exacerbated in the distribution of goods and opportunities. The basic point of equality as a normative principle is not that everyone have similar things or achieve similar outcomes, that would be undesirable both for reasons having to do with individual liberty as well as social need. Just as individuals may desire or be capable of different things, so too will society benefit not from everyone being exactly alike but rather reflecting a diverse array of perspectives, talents, and skills. But as a normative principle equality can help us do three things: first, it can help us to identify the inequalities that matter from a moral point of view. Second, it can help us to figure out how we might design or reform our social institutions so as to reduce, and in some cases perhaps even eliminate, unfair inequality. Third, it can help us to navigate hard decisions concerning the distribution of resources and opportunities.

\section{Which Inequalities Matter?}

Some of the most basic philosophical work to be done involves simply identifying which kinds of inequalities matter from a moral point of view. This is not always an easy task. To illustrate, consider the following case. Clark is an avid jazz enthusiast, and over time, he has accumulated a large record collection. In the general distribution of societal goods, Clark's having amassed a large record collection arguably is not morally 
significant. Though his emotional or spiritual life may be enriched on account of the music he has at his disposal, and he may enjoy sharing his knowledge and experience with other jazz aficionados, his having this record collection per se does not advantage him relative to the goods and opportunities available to others. And though he may imagine it to be otherwise, the quality of an ordinary life does not hinge on knowing anything about jazz, as absurd as this may sound to Clark.

But if we widen the lens just a bit, we also notice that Clark was born into a middle-class family with well-educated parents; not only did they cultivate his love of music, they too are career musicians. These more detailed background conditions - in particular who his parents are - have benefited him in myriad ways, including his genetic traits, the neighborhood in which he grew up (within walking distance of a magnet school specializing in music), the private music lessons he has enjoyed, his music-loving peer group, the conservatory where he chose to study, the mentors with whom he came into contact, and the kinds of intrinsically rewarding work he later pursued. Thus taken in isolation, the record collection is neither here nor there with respect to equality. But, the more information we have about Clark, the more his record collection appears to constitute a larger set of facts about his advantages that are morally significant from the standpoint of justice. Further, given the scarcity of satisfying musical careers for which Clark's experiences undoubtedly provide an advantage, there are reasons to believe that many of the rewards that he enjoys for his choices, hard work, and talent are not, strictly speaking, deserved.

Yet, while we may recognize Clark's undeserved advantages, many of us still will be inclined to view the rewards he enjoys for his musical talents as being well-deserved. After all, talent and hard work should count for something; if they didn't, there would be very little incentive for many persons to work hard or cultivate their latent talents and skills, pursuing excellence. Excellence in particular seems to have an independent value of its own that we have reason to value. Thus, arguably, while Clark may not deserve his traits or circumstances over which he has no control, it is still acceptable from the standpoint of justice that he benefit from choices that he has made, just as it is acceptable that he be held to account for what he has chosen to do or not do.

But this is too quick, for there are at least three difficulties that immediately arise. The first difficulty is that it will be virtually impossible to separate Clark's talent, motivation, and hard work from the background conditions under which they have developed. After all, his choice to take up an instrument, devote himself to weekly tutorials and daily practice, take advanced placement musical theory courses in his magnet school, listen to a great deal of music in his free time, and pursue both a college degree and career in music correlate very strongly with his (undeserved) background conditions in which his choices were made. Hence, the benefits Clark enjoys as a result of his musical interests, talents, and hard work might still be seen as morally problematic.

A second difficulty is that while Clark's talents, work ethic, or even his love of music are undeserved, this in itself is no argument against further cultivating his interests, or developing his talents, now that they are known and both his passion and motivation for music has been discovered. Even if we adopted a prioritarian principle that would require devoting more resources music teachers, instruments, sheet music - to those less fortunate than Clark, that would be no argument for neglecting Clark; equality would still require that we also treat him fairly, and not only those less fortunate than himself. Indeed, an interpretation of equality that ignored (or minimized) the interests of Clark, or for that matter the majority population which may not concern itself with musical pursuits, would be problematic from the standpoint of justice. But so, too, would an interpretation of equality that would fail to cultivate the talents of the more advantaged simply because they acquired their talents unfairly. Possessing talents that are undeserved is not a decisive argument against cultivating them nonetheless, especially if - as is likely in many cases - doing so will yield benefits for many others. Demonstrating the public benefits arguably strengthens the case for cultivating undeserved talent. Yet, even when a particular 
talent may not produce such obvious public benefits - many highly talented musicians have great difficulty procuring steady employment fairness constraints still require that we not neglect said persons simply because their talent is undeserved.

The third difficulty is one of distribution. This is because the kinds of inequalities that we encounter in this case, represented by Clark's musical interests and talent, are not the kinds of things that are easy to distribute. Even with similar opportunities to take up music, it is reasonable to assume that not everyone will share Clark's interest, talents, or self-discipline where music is concerned. However, if, as Aristotle believed, a musical education is crucial to human flourishing (and hence relevant to justice concerns), then there still is a great deal we can do to mitigate the unfairness of persons like Clark enjoying a rich musical education and training, while countless others receive none.

For instance, motivated by the principle of equality, a strong case for a compulsory musical education can be made, rather like the principle of equality has motivated the establishment of public systems of education in countries around the world; or how it has led to the redistribution of extra resources to children born into poverty, or who have disabilities; or how it has motivated the revision of curricular content whose purpose was to tell the neglected histories and perspectives of minority groups; or how it has been used to incentivize millions of individuals to use their motivation and talents for public service.

The upshot is that we may not be able to ensure that everyone has the same childhood experiences, or cares about the same things, or pursues comparably rewarding careers. At the same time, we could insist that the distribution of goods, resources, and opportunities be distributed as fairly as possible. As the foregoing illustration suggests, this might include a compulsory music education. To the extent that we can do this, we will have done a great deal to mitigate egregious inequality and perhaps even to have levelled the playing field much more than would have been the case had equality not been the operative principle.

\section{Equality of Educational Opportunity}

As a more specific articulation of equality, equality of opportunity dictates that in the distribution of opportunities in any given society, the competition should be fair. A more Rawlsian articulation of the principle holds that persons similarly talented and motivated should enjoy fair chances in the competition for public offices and social positions. That is, persons with similar native endowments (talent and ability), and the initiative or motivation to put those talents to effective use, ought to have more or less the same opportunities to do so irrespective of their family and social class origin. However the principle is stated, there are several attending difficulties.

Surely one is that even a ringing endorsement of the principle from all sides of the debate will not settle the matter concerning the need to interpret the relevant terms in ways satisfactory to all parties. A second difficulty is that equality of opportunity, as the principle is discussed in political philosophy and theory, is almost always applied to the institutional structures of nation states. While cosmopolitan justice theory has endeavored to extend the equality principle to global concerns (e.g., trade, immigration, debt relief, climate change, etc.), it is difficult to see how equal opportunities on this scale are even remotely realizable. Indeed, it is exceedingly difficult to achieve this even at the state level in all but the smallest and most homogenous societies. A third difficulty, one I return to later, is this: there inevitably will be trade-offs between equality and other principles, and as often as not these tradeoffs cut against equality.

In recent years, two perspectives on equality of opportunity have come to dominate much of the discussion vis-à-vis educational justice. On the one hand are "sufficientarians," who apply the egalitarian principle not by concerning themselves with inequality gaps - between rich and poor, say - but rather by determining what the minimal threshold necessary for a decent life ought to be. Certain deficits, e.g., malnourishment, are inherently bad irrespective of whether others suffer from the same deficit; adequate nourishment, then, is a 
nonfungible good. With respect to education, sufficientarians argue that the threshold must be adequate to participate in democratic politics as an equal member of society. Satisfying the level of adequacy for everyone up to the threshold is what matters, and no one should be permitted to fall below that threshold. Inequality is permitted above but not below the threshold; accordingly, important restrictions are imposed on the kinds, but also on the degree, of inequality permitted.

On this reading of equality, determining precisely how and which resources should be redistributed above the threshold can only be determined by democratic deliberation within a particular context. For example, equality may require that more public funding and resources be allocated for special education for the severely disabled, but this is not a foregone conclusion, for the same deliberation could result in extra resources being spent on programs for the gifted. The point is that above the threshold, adequacy theorists allow for discretion in responding to the exigencies of context, as well as variable human circumstances and need.

From the other side of this debate are those who object to the concern with "adequacy" on the grounds that it allows for too much inequality above the threshold. On this reading of equality, priority should be given to the least advantaged, full stop. Thus in the education domain, it ought to be the poor, disabled, and marginalized who are given priority in the distribution of scarce goods and opportunities. If more scarce resources are devoted to the disadvantaged than the majority or the most talented, egalitarians of this ilk insist that some priorities - alleviating disadvantage simply trump adequacy standards. If this means that the disadvantaged receive more scarce resources than others, then so be it. Thus on this reading of equality, unfair inequalities may be permitted only when there are other reasons for allowing and even promoting them, for example, so that important benefits redound to the less advantaged.

Irrespective of which of these interpretations one prefers, both are amenable to robust egalitarian interpretation and application. Similar outcomes - both of which incidentally also permit considerable inequality - can be reached by adopting either interpretation. As with most ethical dilemmas, much will depend on the way in which the different principles are understood and applied, the variables in each case, the abundance or scarcity of resources, and the possible outcomes specific policy decisions may have. For instance, both will need to decide where the baseline for equality must be set, and moreover what it must be set for. Should the minimum threshold of equality require that material resources be equally distributed? Which content should be required to satisfy a minimum threshold? How might the preferences of individuals (e.g., teachers, parents) factor into these decisions? Even if we succeed in answering these questions, we still must address the matter of how much inequality above the threshold should be permitted.

\section{Trade-Offs}

Making matters more complex, equality is not the only game in town. Because there are equally strong reasons to care about other values and principles (e.g., liberty, excellence, cultural membership, family intimacy, etc.), there inevitably will be difficult trade-offs. To illustrate these tensions, let us look at one of them more closely.

\section{Parental Partiality}

Parental partiality (PP) is meant to capture the special reasons why parents are morally justified in lavishing time, attention, and love on their own children. With few exceptions, parents are better placed than most to know, understand, and attend to their own children's needs, and, if paired with unconditional love from a parent, this is undoubtedly in the child's interest. If all parents were more or less equally positioned (in terms of location and environmental conditions), well-equipped (in terms of intelligence, education, resources, time) and disposed (in terms of emotional and physical strength, temperament, and habituation) to care for their children, there might be a sense in which we could speak of equality. 
But we all know that the reality is different, and the child who is loved enjoys an important advantage over children who are not loved very well, or even not loved at all. Hence as with other kinds of goods, the unequal distribution of love and attention, too, is a matter relevant to egalitarian justice. And it is not just children who benefit from the intimate relations of a family. In addition to the duties of partiality that parents have toward their own children, parents, too, have an important interest in loving their own children. Indeed, the lives of parents generally go better when they are able to invest themselves in nurturing and raising children, provided of course they have the requisite amount of resources and time, not to mention a temperament suitable to parenting.

Now just because parents have valid duties and interests vis-à-vis their own children does not mean that they are permitted to do whatever they want. For instance, parents who fail - whether through abuse or neglect - in their duties to raise their children to a minimally acceptable level may be forced to forfeit this prerogative; indeed, the state may take children away from their parents because they commit, in the words of Mill, a "moral crime." Moreover, not all expressions of PP are allowed to trump other concerns. But as a general rule, parents are permitted (indeed encouraged) to do more for their children than they do for others as a matter of justice.

It runs counter to our intuitions that we ought to adopt Plato's radical proposal and abolish the family in order to erase the inequality; equally uninviting is the idea that we ought to "level down" the benefits of intimacy, i.e., deny some children love as a way of redressing the imbalance. Putting aside the logistical improbabilities, both strike us as entailing larger offenses against justice. Yet surely one abiding difficulty here, as we saw earlier with the example of Clark, is that the benefits of love and affection are borne out of intimate relations, and these cannot - indeed must not - be "distributed" in the same way that other kinds of resources can without violating important moral obligations one has to one's own child. So there is a hard tension here, one that demands some kind of trade-off.
Of course trade-offs need not be a zero sum game; principles can complement and reinforce one another. For example, whereas liberty and equality are frequently in tension, this need not always be the case: equality also entails securing equal liberty for all. Though it is often the case in the real world, taking equality seriously would mean that wealthy citizens should not enjoy greater influence in the exercise of their political liberty than poor citizens. Similarly, equalityvaluing parents who can offer reasons for favoring PP over equality measures that would diminish that value still may insist that something rather than nothing be done about the unfair inequalities affecting the lives of other families, especially if inequality can be measurably diminished. Hence the principle of equality can motivate us to challenge unfair advantages and to think hard about how to improve upon the existing situation. But of course if we are to be serious about our egalitarian principles, then we also will want to make a candid assessment about (a) whether our preferred values or principles are in fact self-serving, and (b) whether our beliefs about how best to mitigate equality can be supported by empirical evidence.

\section{Appling Egalitarian Principles to the Real World}

As the foregoing discussion clearly indicates, a number of theoretical difficulties already attend simply interpreting and prioritizing equality. Yet, matters become immensely more intricate once we begin applying these theoretical understandings to the real world. This does not mean that ethical difficulties are unresolvable; it does, however, mean that they are complex, particularly, as we have seen, when the principle of equality is amenable to different understandings and applications. Rather than using equality as a shibboleth for meting out justice, we will need to be alert, first, to the tensions that inevitably arise when equally valid principles work at cross-purposes and, second, to the particulars of individual cases, where it is important that we consider all of the relevant variables - including possible risks and benefits. From either side of this debate, there 
doubtless will be different intuitions about what it is possible to equalize, which thresholds matter, where the lines should be drawn, and, given the inevitability of hard tensions, about whether and when it is it is morally responsible - versus morally complacent - to make a trade-off. To see how equality might be applied in the real world, consider two strategies relevant to educational justice.

\section{Weighted Pupil Funding}

As a redistributive measure, weighted pupil funding (WPF) roughly requires increased per pupil spending for students with greater educational needs, such as children with disabilities or whose parents earn below the official poverty line. The aim of WPF is both to compensate for disadvantage and improve educational opportunity. As an egalitarian measure, WPF can make an important difference: it can prevent schools saddled with more acute disadvantage from slipping further behind. Egalitarians strongly support WPF, believing that it is an effective way to mitigate poverty. But how well does WPF do in mitigating inequality? Below are some reasons to guard against unwarranted optimism.

First, though it can mitigate some of the effects of disadvantage, WPF tells us very little about how the additional resources contribute to a child's learning. After all, school boards allocate WPF in various discretionary ways, and it remains difficult to determine precisely how and what the relevant effects are. Second, WPF does nothing to prevent schools having poverty concentrations in the first place. That is, WPF does not address neighborhood effects, nor does it address the fact that poor neighborhoods, and the families who live there, are disadvantaged in a variety of other respects. Third, and relatedly, WPF does nothing to subtract from what more privileged families are able to enjoy by simply avoiding high poverty schools and neighborhoods in the first place. Thus to support WPF and PP in equal measure is effectively to leave the most relevant kinds of inequality undisturbed, i.e., those that occur outside the school generally, and within the sphere of intimacy more specifically.

As a general rule, redistributive accounts of equality involve beliefs about how justice will be accomplished once spending amounts are equitable. There is no question that justice requires that spending amounts - and the distribution of material resources generally - ought to be fair, i.e., proportionate to need. Yet the difficulties with redistributive accounts concern beliefs about (a) which resources matter and (b) whether any amount of resources available in the school can meaningfully compensate for the priceless resources generally unavailable to poor pupils outside the school. These include but are not limited to: table talk, college and career advice, homework assistance, museum visits, crosscultural exchanges, etc., all of which are typical of the middle- and upper-class habitus. The upshot is that one can wholeheartedly endorse full equity with respect to resource distribution - including, in the educational domain, the use of WPF - while simultaneously invoking all of the nondistributive benefits of PP insofar as this entails the transference of social capital.

Thus while WPF certainly can help to alleviate the effects of poverty and disadvantage, as a policy instrument its effects in compensating for social disadvantage are ambiguous at best. First, it does not guarantee that the right services will reach the right students, and second, it does nothing to compensate for what children lack outside of school. These observations are not an argument against WPF; rather, they serve to underscore the importance of coupling this strategy with other, much broader, equality-motivated resources and interventions. What remains improbable, however, is whether the most relevant equalitypromoting resources - ones normally associated both with family life and what John Ogbu called "community forces" - can be redistributed in the first place.

\section{School Integration}

Yet another strategy motivated by the equality principle is school integration. Integrationist arguments typically maintain that schools integrated by race/ethnicity and especially social class will improve the peer effects, which means that children can learn at least as much from each other as they do from their teachers. Further, equalitymotivated integration arguments are predicated 
on the belief that the presence of more middleclass children in the school translates into greater overall parental involvement, and these benefits will redound to families with less social capital. A related belief is that schools with more middleclass children will assist in retaining teachers, which contributes to the stability of the school. Again, these beliefs are widely endorsed among egalitarians. Even so, there are many difficulties with the integration-for-equality account.

Surely one problem is to conflate desegregation or spatial mixing with the more demanding conditions of true integration, which presumably would ensure real equality of opportunity. And for equality of opportunity to get any traction at all, there first would need to be equality of recognition, status, and treatment. Again, equality of treatment here would not entail sameness, but, rather like the egalitarian logic driving WPF, it would be proportionate to need. But the integration-for-equality beliefs that maintain that mixed schools will - or are even likely - to produce outcomes of equality is difficult to reconcile with virtually everything empirical research has reported about mixed schools for the past half century. Indeed, it has become a platitude to observe that school systems - such as they currently are - largely serve to reproduce inequality, and the more mixed the school is (by social class, but also by ability, ethnicity/race, and even culture/religion), the more stratified the educational experience in that school we should expect.

Now while there is evidence that schools with more middle-class children succeed in retaining their staff at higher rates than high poverty schools, there is little evidence to support the claim that (a) the best teachers are assigned to teach the pupils with greatest need or (b) that either peer groups or classrooms - beyond the age of eight or nine - are very heterogeneous with respect to social background or ability, no matter how mixed a particular school might be. Indeed, most schools, including most magnet schools that were designed to mitigate segregation, continue to be organized to benefit the more privileged students, and in several European countries children are selected as young as 10 or 12 - largely along social class lines - to follow different tracks of secondary education. Further, as we saw with WPF, school integration accounts also largely ignore the enormous gap separating what children do with their (preferred) peers and families outside of school.

With respect to the idea that the involvement of more middle-class parents will somehow benefit less fortunate children in the school, this is an egalitarian belief devoid of any corroborating evidence. It is true that schools with a higher concentration of well-educated parents often bring more resources with them. But parents with more social capital principally concern themselves with navigating the system in order to benefit their own child, for instance, by pressuring school officials to create a gifted/talented track, challenging staff decisions regarding class assignment, or to simply switch schools when things do not go their way. Again, these observations are not an argument against school integration per se; in rare instances, an integrated school can live up to egalitarian ideals. At the same time, egalitarian arguments for integration too often fail to come to terms with the fact that a mixed school is almost never a proxy for educational justice.

\section{Final Thoughts}

All egalitarian liberals agree on the importance of equality as a moral principle. Yet judging by what egalitarian liberals are willing to permit - viz., all kinds of inequality above an acceptable threshold - we appear to be caught in an ethical quandary. With respect to educational justice more specifically, at least two major difficulties stand in the way.

The first difficulty of egalitarian liberal accounts of educational justice is the almost exclusive attention given to the institutional features of education, i.e., schooling. The institutional focus is understandable, given that accounts of justice are more likely to be viewed as legitimate when restricted to the public domain. When the state does interfere in the private domain - such as in cases involving abuse or neglect - at the level of principle it is with a view to protecting the rights, liberties, and 
opportunities of vulnerable individuals. Yet at the empirical level, legitimate state interference almost always transpires after an injustice has been done. Proposals that argue for earlier intervention with a view to preventing inequality from worsening - such as monitoring parenting behaviors, requiring parenting classes, or mandating preschool attendance - are often seen as needlessly intrusive for what they suppose about "good parenting" and also for how they meddle in the private affairs of family life.

To counter this, a few egalitarian liberals have argued that we ought to ban elite private schools (in the UK) or elite publics (such as gymnasia in Europe). Related arguments insist that parents ought to "level down" in other ways, so that either more privileged children, including one's own children, receive less than what they deserve in terms of an equal educational opportunity. Putting aside the highly speculative nature of these philosophy seminar room proposals, none of them escape other kinds of problems. It is true that banning elite schools may reduce the institutional options available to wealthier parents and doing this may interrupt the furtherance of certain privileges. Yet it is doubtful whether this will do anything to interrupt the social networking that matters most; nor would these proposals likely prevent other strategies from being pursued, such as selecting alternative schools, homeschooling or afterschool tutoring - each of which currently enjoy enormous popularity, and not only among the more socially privileged. And in any case, with respect to levelling down, there are reasons to think this will simply offend against justice as it concerns the educational needs of the privileged.

A second difficulty, one that we have already seen, is that nearly all egalitarian liberals, irrespective of where they stand vis-à-vis adequacy standards, embrace the special prerogatives parents enjoy to shape and direct aspects of their children's lives. These are inescapably hard tensions because persons committed to egalitarian principles can - on the most charitable reading invoke another principle that allows one to say that justice is "unreasonably demanding" when it infringes on other things one has reason to value.
PP is quintessentially that principle, and, as we have seen, more often than not its exercise cuts against equality. Certainly the duties that parents have to their own children constitute an important element of justice. At the same time, it is precisely these prerogatives where the real obstacles to equality lay, with respect to educational opportunity or opportunity tout court. And thus perhaps the most disturbing outcome as it concerns equality is that we can happily endorse egalitarian policies while giving up nothing of real value where equality appears to matter the most.

\section{Further Reading}

Anderson, E. (1999). What is the point of equality? Ethics, 109(2), 287-337.

Arneson, R. (2013). Equality of opportunity: Derivative not fundamental. Journal of Social Philosophy, 44(4), 316-330.

Barry, B. (1988). Equal opportunity and moral arbitrariness. In N. E. Bowie (Ed.), Equal Opportunity. Boulder: Westview Press.

Brighouse, H., \& Swift, A. (2009). Legitimate parental partiality. Philosophy and Public Affairs, 37(1), 43-80.

Clayton, M., \& Stevens, D. (2004). School choice and the burdens of justice. Theory and Research in Education, 2(2), 111-126.

Cohen, G. A. (1989). On the currency of egalitarian justice. Ethics, 99(4), 906-944.

Fishkin, J. (1983). Justice, equal opportunity and the family. New Haven: Yale University Press.

Jencks, C. (1988). Whom must we treat equally for educational opportunity to be equal? Ethics, 98(3), 518-533.

Mason, A. (2006). Levelling the playing field: The idea of equal opportunity and its place in egalitarian thought. Oxford: Oxford University Press.

Merry, M. S. (2013). Equality, citizenship and segregation. New York: Palgrave Macmillan.

Rawls, J. (2001). Justice as fairness: A restatement. Cambridge: Cambridge University Press.

Roemer, J. (1998). Equality of opportunity. Cambridge: Harvard University Press.

Satz, D. (2007). Equality, adequacy, and education for citizenship. Ethics, 117(4), 623-648.

Scheffler, S. (2003). What is egalitarianism? Philosophy and Public Affairs, 31(1), 5-39.

Sen, A. (1980). Equality of what? The Tanner lectures on human values.

Sher, G. (2014). Equality for inegalitarians. Cambridge: Cambridge University Press.

Vallentyne, P. (2002). Brute luck, option luck, and equality of initial opportunities. Ethics, 112(3), 529-557. 